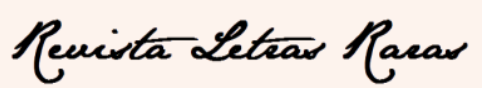

ISSN: $2317-2347$ - v. 8, n. 3 (2019)

\title{
Formação inicial de professores de língua inglesa e letramento crítico: um diálogo desejável? ${ }^{1}$ / Pre-service language teacher education and critical literacy: a fruitful dialogue?
}

\author{
Jhuliane Evelyn da Silva* \\ Marco Antônio Margarido Costa**
}

Recebido em 15 jun. 2019. Aprovado em 25 ago. 2019.

Como citar este artigo:

SILVA, Jhuliane Evelyn da; COSTA, Marco Antônio Margarido. Formação inicial de professores de língua inglesa e letramento crítico: um diálogo desejável?. Revista Letras Raras. Campina Grande, v. 8, n. 3, p. Port. 36-64 / Eng. 37-63, set. 2019. ISSN 2317-2347.

DOI: http://dx.doi.org/10.35572/rlr.v8i3.1444.

\section{RESUMO}

Colocando a pós-modernidade como pano de fundo desta pesquisa, propomos demonstrar como alunosprofessores em formação inicial do curso de Licenciatura em Letras - língua inglesa da Universidade Federal de Campina Grande se engajaram em atitudes críticas/práticas problematizadoras em situação de estudo. Para tanto, empreendemos uma investigação qualitativa, descritivo-analítica e utilizamos respostas a uma entrevista semiaberta e a uma narrativa que lidavam com o processo de formação docente e a relevância da língua inglesa para a prática desses futuros docentes. A análise utilizou as lentes do letramento crítico de viés pós-estruturalista (MENEZES DE SOUZA, 2011a, JORDÃO, 2014, PENNYCOOK, 2012) por ser uma abordagem que centraliza o questionamento, a produção de significação e a construção de conhecimentos situados e parece se alinhar criticamente ao que estamos entendendo enquanto demandas de um mundo pós-moderno (BAUMAN, 2007). Os dados gerados indicam que, em situação de estudo, os participantes manifestam criticidade principalmente a partir de falas que revelam questionamentos, desnaturalização e construção de entendimentos outros em um movimento formativo processual e não linear.

PALAVRAS-CHAVE: Formação inicial de professores; Língua Inglesa; Letramento Crítico.

\begin{abstract}
By having postmodernity as the background for this research, this article demonstrates how student teachers in a pre-service language teacher education at the Federal University of Campina Grande/PB engaged in problematizing practices during their classes in the university. To do so, the authors carried out a qualitative, descriptive-analytical investigation that used answers to a semi-open interview and a narrative regarding the teacher education process and the relevance of English to their future practice. Post-structuralist critical literacy (MENEZES DE SOUZA, 2011a, JORDÃO, 2014, PENNYCOOK, 2012) was adopted to analyze the participants' criticality since it was seen as an approach that both stresses questioning, meaning-making and situated knowledge and seems to critically respond to the demands of our postmodern world (BAUMAN, 2007). Results indicate that the participants manifest criticality when engaging in questioning, denaturalization, and construction of plural understandings in a processual and non-linear formative movement.

KEYWORDS: Pre-service teacher education; English language; Critical Literacy.

\footnotetext{
${ }^{1}$ Este artigo é um recorte modificado da dissertação de mestrado de Silva (2015).

* Doutoranda em Letras pela Universidade Federal do Paraná - UFPR, Curitiba, Paraná, Brasil, anecomjesus@gmail.com

** Doutor e mestre em Letras pela Universidade de São Paulo - USP, São Paulo, Brasil. Professor Associado da Universidade Federal de Campina Grande - UFCG, Campina Grande, Paraíba, Brasil, marcoantoniomcosta@gmail.com
} 


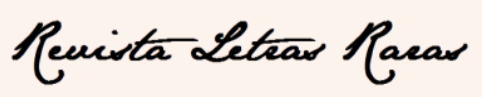

ISSN: $2317-2347$ - v. 8, n. 3 (2019)

\section{Introdução}

Para tratar da relação entre a formação inicial de professores e o letramento crítico de maneira que a discussão coloque em relevo as crises pelas quais estamos passando, bem como as complexidades próprias da sala de aula, colocamos a pós-modernidade como pano de fundo da nossa pesquisa. Nos tempos líquidos em que vivemos, encontramo-nos entrecruzados e constituídos por uma mudança de paradigma marcada pelo questionamento e pela crise que traz implicações e necessidades de transformação em todas as áreas da vida social, haja vista a impossibilidade da totalidade, da completude e da fixidez próprias da sociedade sólido-moderna (BAUMAN, 2001, 2007).

No campo educacional, contexto investigado neste trabalho, tais mudanças atingem principalmente os conceitos de conhecimento e de sujeito (KUMARAVADIVELU, 2013). Na modernidade sólida, persiste a lógica iluminista que entende o conhecimento como estando fora do sujeito e existindo independente de suas vivências. Assim, ele é entendido como sinônimo de "domínio dos fatos objetivos e científicos" (SILVA, COSTA, 2017, p. 104), fruto "do monopólio" da ciência sobre a “distinção universal entre o verdadeiro e o falso" (SOUSA SANTOS, 2007, p. 72). Neste viés, tal conhecimento deve ser transmitido e apreendido "em função de uma estrutura curricular que favorece um sequenciamento linear e descontextualizado de aprendizagem, pautado basicamente em conteúdos gramaticais" (LOPES, 2013, p. 953), como pode ser observado no ensino de línguas no Brasil. Em tempos líquidos, porém, tal conceito desvincula-se da visão estrutural para a existência, a validação e a necessidade de construção de múltiplas formas de conhecimento, exigindo agência tanto do professor quanto do aluno. Como Jordão aponta em uma entrevista, "precisamos de ações subversivas, pontuais, que contrabandeiem no sistema imposto práticas diferentes, práticas que demonstrem a possibilidade da diferença, a produtividade de se existir em meio à diversidade" (JORDÃO, 2017, p. 193, ênfase no original).

A noção de identidade, por sua vez, antes atrelada à família e à comunidade de origem, condicionada por normas sociais cristalizadas e cristalizantes, começa a ser questionada e vista mais internamente como construída do que externamente condicionada na modernidade líquida. É, assim, uma identidade fragmentada, múltipla e 


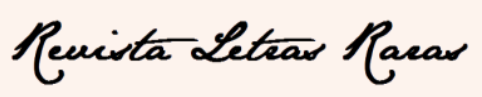

ISSN: $2317-2347$ - v. 8, n. 3 (2019)

expansiva que confere ao sujeito um grau de agência para a tomada de decisões e para a prática situada e criticamente informada na sociedade (cf. KUMARAVADIVELU, 2013). Como resultado da crise da modernidade sólida, temos a presença de identidades ambivalentes, transitórias e que se encontram em diversos espaços do continuum existente entre fixo e fragmentado, coexistindo, não pacificamente, nessas diferentes perspectivas.

Tangenciando para o Eu professor, subjetividade com a qual estamos lidando, essas características podem ser materializadas no processo de busca constante de um Eu que atenda às expectativas do aluno e da sociedade, um professor que vá ao encontro do aluno, ao mesmo tempo em que lhe dê espaço para caminhar e descobrir(-se) sozinho, que seja criativo e lide com as imprevisibilidades, que planeje levando em consideração o contexto do seu alunado, ou ainda que seja capaz de construir saberes implicando o aluno neste processo. Mas, além de professor, um agente político que participa na tomada de decisões de sua comunidade e do contexto mais amplo - histórico, econômico, ambiental, social - do qual faz parte (FREITAS, 2004).

Ainda, colocamos em relevo as identidades por estarmos tratando de participantes que escolheram assumir papéis de professores dentro da atual conjuntura líquidomoderna. Esses, ainda em formação inicial, também comungam da fragmentação, da dúvida e da fluidez presentes no ser moderno e pós-moderno, tão característico desse momento. O desejo do poder e da transmissão de conhecimentos e a busca pela certeza aliam-se à dúvida e ao desconforto de estar em um entre lugar (BHABHA, 1998).

Ao direcionarmos a discussão para o campo educacional, acreditamos que a ressignificação dos conceitos de conhecimento e de sujeito aqui proposta urge mudanças na educação - nos papéis de professor e de aluno, nos objetivos educacionais, nas formas de planejamento e construção das aulas, bem como na avaliação, enfim, na formação do professor, permitindo, portanto, o derretimento do que era sólido e o tornando maleável, fluido e flexível, apto à transformação (COSTA, 2008). Entendidos por este viés, a diferença, a crise e o dissenso não mais possuem conotações negativas, uma vez que passam a ser entendidos como elementos constitutivos do ser humano.

A transformação sobre a qual falamos urge uma mudança de atitudes. Assim, sublinhamos a criticidade como fulcral para o processo de formação docente. Neste trabalho, entendemos o termo como crise (RICOEUR, 1977 apud MONTE MÓR, 2013), como ruptura de um modelo tradicional. Como nos alerta Kumaravadivelu (2012, p. 14), 


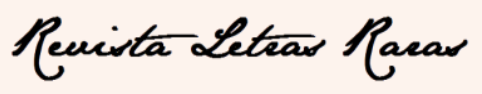

ISSN: $2317-2347$ - v. 8, n. 3 (2019)

devemos almejar uma ruptura epistêmica, isto é, "Uma profunda reconceituação e reorganização de sistemas de conhecimento", ${ }^{2}$ que reconheça a modernidade e a colonialidade de nossos dias, de nossas instituições e nossas atitudes, bem como suas consequências e implicações para a sociedade e para a educação em geral, com vistas a mudá-las. Essa ruptura epistêmica pode ser traduzida em atitudes diárias e necessárias como estar aberto ao diferente (o diferente sendo a regra, e não a exceção), aprender a (des)aprender (SPIVAK, 2004, FABRÍCIO, 2017), ver além do que estamos acostumados, questionar o que vemos, olhar para a sala de aula como um local complexo, ser sensível a ele e ver os alunos para além daquele espaço (JORDÃO, 2017), validar outras formas de entendimento que não somente as racionais, ou ainda criar alternativas locais que se apropriem, ressignifiquem e resistam aos discursos, como os neoliberais, para a construção de outros sentidos.

Elegemos a acepção do termo acordando com o sentido conferido por Ricoeur (1977 apud MONTE MÓR, 2013) por buscar o desenvolvimento da criticidade dos sujeitos e a agência por meio do questionamento de si, do outro e do mundo. Ou ainda por Pennycook (2012), que a entende enquanto uma prática problematizadora que, menos que respostas, almeja incitar a dúvida sobre nossas categorias já naturalizadas e sobre nossos entendimentos de nós mesmos e do mundo.

Nosso interesse em analisar o desenvolvimento da criticidade por meio de atitudes de questionamento e de ações situadas realizadas a partir do contexto vivido respalda-se em pesquisas como a de Duboc (2012), que discute a importância de se realizar atitudes curriculares situadas para a formação crítica do futuro professor de inglês, bem como a de Duboc e Ferraz (2011), que trata da transposição para a sala de aula de inglês de debates globais recentes. Além desses estudos, inspiramo-nos em Mattos (2011), que revela a possibilidade de realizar um trabalho mais crítico e em prol do desenvolvimento de um cidadão agente, crítico e questionador e, na pesquisa de Costa (2012), que aborda a implementação da tecnologia nas aulas dos alunos em formação inicial por meio de práticas de Letramento crítico, como forma de adequação à sociedade atual em um viés crítico.

\footnotetext{
2 “An epistemic break, then, represents a thorough re-conceptualization and a thorough re-organization of knowledge systems.",
} 


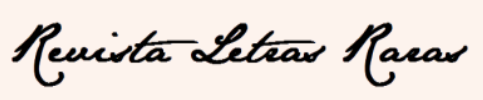

ISSN: 2317-2347 - v. 8, n. 3 (2019)

Neste artigo, portanto, pretendemos demonstrar como os alunos-professores em formação inicial de um curso de Licenciatura em Letras - língua inglesa ${ }^{3}$ se engajaram em atitudes críticas/práticas problematizadoras em situação de estudo. Para que isso seja possível, utilizaremos respostas a uma entrevista semiaberta e uma narrativa que lidavam com o processo de formação docente e a relevância da língua inglesa para prática desses futuros docentes. Faremos isso a partir dos pressupostos do letramento crítico de viés pósestruturalista por ser uma abordagem que também centraliza o questionamento, a produção de significação e a construção de conhecimentos situados e parece se alinhar, criticamente, ao que estamos entendendo enquanto demandas de um mundo líquidomoderno. Nosso argumento é o de que se queremos mudanças capazes de acompanhar a perspectiva líquida que se impõe, torna-se imprescindível que consideremos as crenças, as vozes e as ações dos professores, dos alunos e de todo sujeito envolvido no processo de ensino-aprendizagem, de modo a desenvolver seu senso crítico por meio da construção dialógica de sentidos (KUMARAVADIVELU, 2013).

Além desta Introdução que tratou de mostrar um panorama sobre as mudanças impulsionadas pelas crises da modernidade sólida com foco nos conceitos de conhecimento e identidade no contexto educacional, organizamos o artigo em outras duas seções: uma que vai descrever perspectivas críticas de diferentes posicionamentos epistemológicos e ontológicos e outra que vai ofertar uma leitura sobre os dados gerados no contexto supramencionado com foco na criticidade dos alunos-professores. O texto termina com algumas considerações sobre as atitudes dos participantes e o que isso pode sinalizar da formação crítica de professores de inglês.

\section{Pensando no letramento crítico...}

Em face do entendimento de criticidade considerado neste texto, vimos a necessidade de trazer à tona diferentes noções de criticidade no contexto de teorias e abordagens educacionais, para, ao final, discutirmos o que embasa esta pesquisa. Para tanto, trazemos inicialmente três abordagens de educação crítica - leitura crítica, pedagogia crítica e letramento crítico, pois compreendemos que há diversos e distintos

\footnotetext{
${ }^{3}$ Geração de dados ocorrida no período entre novembro de 2013 e abril de 2014. Os instrumentos utilizados com tal propósito foram: notas de campo, entrevistas, narrativas e relatórios de estágio.
} 


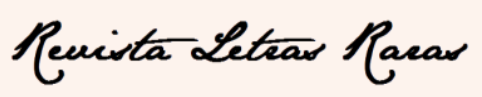

ISSN: 2317-2347 - v. 8, n. 3 (2019)

entendimentos do que seja cada uma, o que alimenta o desenvolvimento de várias perspectivas de leituras, pedagogias e letramentos críticos. Cada posicionamento tende a ter objetivos diferentes e a se fundamentar em pressupostos teóricos e metodológicos igualmente distintos; por isso tratarmos em termos ontológicos e epistemológicos. Ao final da seção, deter-nos-emos sobre o letramento crítico e sobre o porquê escolhemos tal abordagem como parâmetro de criticidade a ser considerado.

A leitura crítica pode ser vista como uma prática de leitura proposta e valorizada pela tradição liberal humanista de letramento de cunho positivista, um letramento pelo qual outras práticas sociais e cognitivas sofreriam o efeito do letramento individual, por meio do qual os sujeitos iletrados passariam a ter suas habilidades cognitivas aprimoradas e como resultado, seriam melhores cidadãos com garantia de acesso aos bens materiais e imateriais (STREET, 2003). Esse tipo de educação crítica tem o objetivo de buscar o sentido do texto conferido pelo autor no momento de sua tessitura. Esse sentido, assim, originaria das intenções do autor ao escrevê-lo. O autor é tomado como o portador dos sentidos e intenções presentes nos textos e o leitor como aquele capaz de fazer inferências e emitir julgamentos, tendo por objetivo o discernimento neutro e racional entre fatos e opiniões (CERVETTI, PARDALES, DAMICO, 2001).

No Brasil, esse tipo de leitura ainda é amplamente utilizado nas escolas de Educação Básica devido à tradição de entender o letramento como decodificação textual. Ser letrado, nessa perspectiva, é ser capaz de reconhecer e reproduzir sons, sílabas, palavras e frases como os únicos elementos produtores de sentido (MONTE MÓR, 2015). Como Street (2014) colocaria, essa prática argumenta em favor da natureza técnica e neutra do letramento, que leva o sujeito ao desenvolvimento de seu pensamento lógico e, por isso, condiz com o modelo autônomo de letramento, que concebe conhecimento como uma competência individual e cognitiva, adquirida por meio da experiência sensorial do mundo e da racionalização e a realidade como referentes e fixas, passíveis de interpretação correta. O objetivo desse tipo de leitura é, em consequência, o desenvolvimento de habilidades cognitivas cada vez mais aprofundadas - e próximas da verdade/realidade - de interpretação textual.

Nessa perspectiva de letramento, a língua é vista como um sistema fechado de regras e, portanto, transparente. Para o trabalho com o texto em sala de aula, as perguntas para discussão possivelmente utilizadas seriam de reconhecimento retórico, 


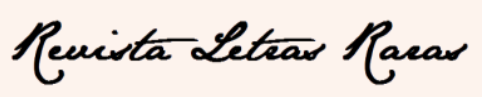

ISSN: 2317-2347 - v. 8, n. 3 (2019)

metalinguístico e contextual (em sentido estrito): o quê? como? quando? para quê? por quê? onde? qual a intenção do autor?

Entendemos que esse tipo de educação crítica trabalha com vistas a solucionar problemas e a promover a mobilidade social numa sociedade moderna (ANDREOTTI; MENEZES DE SOUZA, 2016). Em outras palavras, a leitura crítica como colocada corrobora uma educação neoliberal e bancária como criticada por Freire (1974). A noção de criticidade, portanto, jaz no entendimento do contexto de produção dos textos, no entendimento das intenções do autor, e ainda na capacidade de decodificar a língua e chegar a uma interpretação mais próxima do sentido original almejado pelo autor.

Fundamentada na teoria marxista/neomarxista, a pedagogia crítica (PC) objetiva a justiça social, a igualdade, a transformação e a emancipação dos sujeitos de modo que participem ativamente das decisões democráticas a serem tomadas em uma sociedade assolada por relações de poder sempre hierárquicas e assimétricas que dividem o mundo entre opressor e oprimido, colonizador e colonizado ${ }^{4}$. Essa transformação seria o resultado do desvelamento das verdades, escondidas por trás dos textos, com vistas à libertação de seus leitores. (CERVETTI; PARDALES; DAMICO, 2001, JORDÃO, 2013, MONTE MÓR, 2015).

No Brasil, a leitura das teorias de Paulo Freire e as discussões sobre letramento ideológico de Street $(1984,2014)$ ilustram bem essa pedagogia em outro entendimento de letramento. Freire, nos anos 1960-1980, percebia na linguagem e nas práticas de letramento instrumentos eficazes para a reconstrução social. Para ele, o letramento deveria lutar pela justiça e pela emancipação, com foco no desenvolvimento da consciência do oprimido para além da decodificação, predominante nos cursos de alfabetização até então. Logo, ao ler textos criticamente, os aprendizes deveriam partir de um contexto interpretativo para transformarem-se em atores contracenando frente a situações de opressão e injustiça na sociedade em que viviam. Street (2014) também critica o modelo autônomo e propõe uma visão de letramento como prática social política e ideologicamente situada, dependente das instituições das quais ele faz parte, que varia de um lugar para outro, de uma cultura para outra. Conforme esse autor, o letramento está associado às tecnologias desenvolvidas sócio-historicamente em resposta aos interesses

\footnotetext{
${ }^{4}$ Entendemos que a PC foi pensada por Paulo Freire nos anos 1960 para responder às demandas daquele momento histórico. Ver mudanças em Freire (2005).
} 


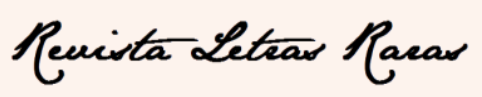

ISSN: $2317-2347$ - v. 8, n. 3 (2019)

da sociedade na qual está inserido e é exatamente por meio dessas tecnologias que a classe dominante exerce poder e controle social.

Em termos teóricos, a PC entende o conhecimento como ideológico, porque está constitutivamente baseado em regras discursivas de uma dada comunidade. Portanto, ele não é neutro ou natural. Ademais, há uma realidade pré-existente ao sujeito e este não a vê como ela é por estar encoberta por um véu ideológico - entendendo a ideologia enquanto estratégias para a dissimulação da realidade, algo inerentemente ruim. Deste modo, a língua é vista como um código ideológico e, por assim ser, dissimula os sentidos "reais" dos textos, restando ao leitor desvelar os sentidos escondidos pela língua. (JORDÃO, 2013, p. 72).

Algumas perguntas que poderiam ser feitas quando do trabalho com textos em sala de aula são propostas por Cervetti, Pardales e Damico (2001) e corroboradas por Menezes de Souza (2011b):

Quem é o público-alvo deste texto? O que o texto afirma? Como o texto tenta convencer o leitor? Que afirmações não são sustentadas? Que mecanismos são utilizados para chamar a atenção do leitor? Que ideias ou palavras são utilizadas para criar uma impressão particular? O que o

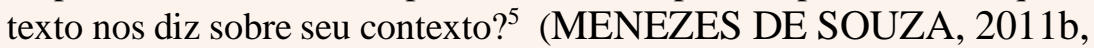
p. 291).

Dito de outro modo, a ênfase da PC em sala de aula recai sobre a escritura do texto, considerando que todas as leituras são homogêneas e, por isso, buscam o consenso. Nossa crítica em relação a esta abordagem está no fato de que ela postula a existência de uma realidade já dada, a existência de uma verdade a ser encontrada, o posicionamento mais ou menos fixo dos sujeitos, e ainda de que a PC tende a não problematizar as suas próprias bases de maneira que entenda a si mesma como uma interpretação e um desejo de verdade. Ademais, parece-nos que ela vê a modernidade sólida como limitada para realizar seus desejos de progresso e bem-estar para todas as pessoas, porém não a rejeita, pois entende que ainda há como recuperá-la se mais vozes (a das minorias, a dos pobres,

\footnotetext{
${ }^{5}$ To whom is the text addressed? What does the text claim? How does the text try to convince the reader? What claims are not substantiated? What attention-getting devices are used? What words or ideas are used to create a particular impression? What does the text show/tell us about its context?
} 


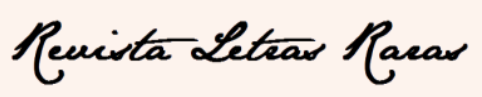

ISSN: $2317-2347$ - v. 8, n. 3 (2019)

a do $\mathrm{Sul}^{6}$ ) forem incluídas nos discursos hegemônicos e se essas pessoas puderem exercer sua agência. (ANDREOTTI, MENEZES DE SOUZA, 2016).

Para tratar do letramento dentro da PC, trazemos linhas gerais sobre alguns de seus vieses. No Brasil, o conceito 'letramento' apareceu pela primeira vez através de publicação de Mary Kato nos anos oitenta, desvinculando-se do conceito de alfabetismo que dominava a educação. Em um primeiro entendimento, tomava-se letramento como prática social mediada pelo uso da escrita, legitimando a heterogeneidade dos usos da linguagem e fincando o conceito em bases etnográficas (ROJO, 2009). Daí a necessidade e a ampla publicação acerca da diferença entre alfabetização e letramento na primeira fase desses estudos em solo nacional.

Segundo percurso de leitura de Duboc (2012), em momentos posteriores, enfocase a utilização de tecnologias outras, que não a escrita, e suas implicações para a sala de aula e para o contexto educacional em geral, colocando em destaque a digitalidade evocada pelos novos letramentos. Lankshear e Knobel (2003), na década de noventa, tratam desses novos letramentos possibilitados pelas novas tecnologias digitais, caracterizadas pelos letramentos pós-tipográficos e não lineares (DUBOC, 2012) que implicam em novos modos de ler, escrever, representar e pensar o mundo.

Outra face dos letramentos amplamente trabalhada no Brasil são os Multiletramentos, termo cunhado pelo New London Group para enfatizar a multiplicidade de mídias e canais de comunicação, bem como a diversidade cultural e linguística atual que, consequentemente, já se faziam presentes nas escolas. Em resposta a esses elementos, o grupo apressou-se em pensar numa pedagogia de cunho inclusivo, que trouxesse à tona o letramento sob o viés da multimodalidade, do multiculturalismo e do multilinguismo, almejando lidar com diferentes textos, gêneros, práticas, linguagens e variedades. Porém, nosso entendimento de criticidade ainda não se vincula a essas abordagens teórico-metodológicas. Pensamos que esses entendimentos de letramento ainda parecem muito engessados e voltados à escrita (formal), ao trabalho com gêneros e podem não dar conta da complexidade da sala de aula e do nosso processo de ação no mundo.

\footnotetext{
6 O 'Sul' é um termo, utilizado por Sousa Santos $(2007,2018)$, que abarca grupos sociais que sofrem/sofreram//tenham experienciado qualquer tipo de sofrimento causado pelo capitalismo, colonialismo e patriarcado de forma sistêmica. Este Sul pode ser composto por países do norte ou do sul geográfico.
} 


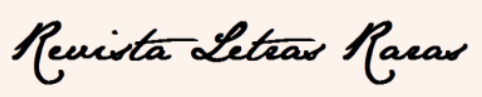

ISSN: 2317-2347 - v. 8, n. 3 (2019)

Por esta razão, elucidamos o letramento crítico $^{7}$ de viés pós-estruturalista ${ }^{8}$ (LC). Este letramento não deve ser entendido como uma metodologia ou uma proposta fechada a ser implementada, mas, sim, "como uma referência para o desenvolvimento de práticas locais" (JORDÃO, 2017, p. 191). Como tal, insiste ver a si próprio como uma construção, um discurso outro que exige responsabilidade e ética para agir no mundo. Dentre seus objetivos, destacamos: ser uma prática problematizadora (PENNYCOOK, 2012), ofertar condições e espaços de aprendizagem para alunos e professores (MENEZES DE SOUZA, 2011b), fomentar uma atitude de suspeita, de questionamento, de diferença e de dissenso como produtivos para a construção de sentidos. Nessa perspectiva, a transformação (objetivada pela PC) veste outra roupagem e significa a transformação discursiva de nossas subjetividades, o que nos permite ver o mundo e a nós mesmos de forma plural.

O LC entende os sentidos, originados na coletividade sócio-histórica dos sujeitos, como sempre construídos na língua e na sociedade. Assim, não há uma realidade fora do texto, pré-existente ao sujeito e à língua, haja vista nossos entendimentos de mundo serem sempre frutos de nossas interpretações - construções sociais validadas pelas comunidades interpretativas das quais fazemos parte. Isso quer dizer que os sentidos da leitura e da escritura do texto são atribuídos a ele no momento da leitura (a leitura e a escrita em si já são atos de produção de textos), que nenhum conhecimento é neutro ou natural, mas, sim, ideológico, situado no tempo e no espaço.

O conhecimento, assim, é construído em uma relação de diferença, de conflito (LOPES, 2013), de modo que se discute atualmente sobre o que se constitui como verdade, para quem, quando, onde, por quê, problematizando e complexificando esta verdade por ser dinâmica e mutável. E se não mais concebemos uma verdade absoluta, temos de "confrontar com as diferenças percebidas nessas outras verdades e relacioná-las aos diferentes contextos que as produziram. O resultado desse processo aponta para o reconhecimento do conflito dos diferentes saberes” (LOPES, 2013, p. 947). Destarte, a

\footnotetext{
${ }^{7}$ São diversas as concepções de letramento crítico existentes. Uma das primeiras e amplamente divulgadas no Brasil é a advogada por Luke e Freebody (1997), a qual lida como uma abordagem que entende a leitura e a escrita como uma prática social situada e que afirma a construção conjunta de sentidos como um de seus pressupostos. Ver Silva (2015) e Cervetti, Pardales e Damico (2001).

8 Segundo Duboc e Ferraz (2018, p. 240), os estudos mais recentes nos letramentos críticos têm demonstrado a expansão na noção de crítica, a emergência de um tipo de questionamento que entende os sujeitos leitor e autor como tendo identidades fluidas e provisórias e a agência situada em práticas de cunho mais localizado. Em virtude desses encaminhamentos, adotamos neste texto o entendimento de letramento crítico redefinido, discutido principalmente por autores brasileiros, como Menezes de Souza (2011a) e Jordão (2013).
} 


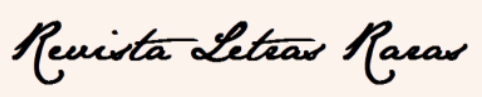

ISSN: $2317-2347$ - v. 8, n. 3 (2019)

reflexão crítica proposta pelo LC busca desnaturalizar o que temos como verdade absoluta, como dado inquestionável, porque verdadeiro. Essa leitura crítica ressignificada urge um posicionamento crítico e reflexivo por parte das pessoas, consideradas interpretadoras (JORDÃO, 2017).

Em consonância com esses pressupostos, o LC enxerga a língua enquanto discurso, isto é, como "um espaço ideológico de construção e atribuição de sentidos que se dá num processo enunciativo sempre contingente (relativo a sujeito, tempo e espaço específicos) numa prática situada de letramento" (JORDÃO, 2013, p. 74).

Para o trabalho com o LC em sala de aula, conforme aponta Menezes de Souza (2011b), as seguintes perguntas são sugeridas:

Qual é o contexto no qual o texto foi produzido? Para que tipo de leitor o texto foi escrito? O contexto de produção do texto é o mesmo em que VOCÊ está lendo o texto? Você é o leitor-alvo deste texto? Como as diferenças nos contextos de produção e leitura do texto afetam seu entendimento? Há um sentido correto, original do texto? Como você se sente em relação a essas diferenças? Devemos eliminá-las? O que fazemos com elas?? (MENEZES DE SOUZA, 2011b, p. 299, ênfase no original).

Como advoga Menezes de Souza (2011a, p. 132, ênfase no original), “o processo de ler criticamente envolve aprender a escutar não apenas o texto e as palavras que o leitor estiver lendo, mas também [...] aprender a escutar as próprias leituras de textos e palavras." Diferente da leitura crítica e da PC, o foco recai em como o sujeito escritor/leitor produz significação. Para além dessa leitura em espaços escolares, autores como Freire (2005) e Menezes de Souza (2011a) apontam que uma leitura que se pretenda crítica deve se debruçar sobre os procedimentos de construção de sentidos e situá-los em seu espaço-tempo para reconhecer que nossas histórias são constitutivamente sociais e coletivas e, portanto, nossas verdades se originam nessa coletividade sócio-histórica a qual pertencemos. Os estudiosos afirmam ainda que, por causa da incerteza e da diferença características do mundo social e valorizadas por esse entendimento de letramento, temos

\footnotetext{
9 "What is the context in which the text was produced? What kind of reader was the text written for? Is the context of production of the text the same as the context in which YOU are reading the text? Are you the reader that the writer of the text had in mind? How do the differences in contexts of production and reading of the text affect your understanding? Is there a "real", "correct", "original" meaning of the text? How do you feel in relation to these differences? Should we eliminate them? What do we do with them?"
} 


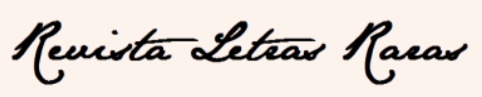

ISSN: $2317-2347$ - v. 8, n. 3 (2019)

espaço para exercer nossa agência com vistas a uma prática problematizadora, situada e transformadora. (PENNYCOOK, 2012, JORDÃO, 2010).

Como consequência dessa percepção, engajamo-nos no conceito de LC que reconhece o rompimento epistemológico-pedagógico com a tradição liberal humanista postulada pelo modelo autônomo de letramento, bem como nos vincula ao entendimento de letramento como uma prática social, não relegando a complexidade, a diversidade e as relações de poder presentes no contexto social contemporâneo. Acreditamos que a educação crítica pode ser pensada tanto por meio do seu afastamento da modernidade e de seus ideais para a criação de alternativas mais sustentáveis e menos desiguais, quanto por meio da aprendizagem a partir dos erros da modernidade (ANDREOTTI; MENEZES DE SOUZA, 2016). Para nós, a criticidade está também no confronto e no questionamento dos projetos da modernidade (como o prestígio, a riqueza acima de tudo e a exploração).

Por mais que se utilize de nossos quadros de referência baseados na razão, essa perspectiva crítica começa a considerar outras formas de conhecimento, como os sentimentos, o corpo, o ler a si mesmo lendo o outro, o escutar o outro, a reflexão e a reflexividade, a complexidade e a contingência, ao mesmo tempo em que a problematização e a ética. Destarte, ainda que se coloque no continuum modernidade sólida-modernidade líquida e que insista numa hiper-reflexividade potencialmente paralisante, o LC embasado em teorias pós-estruturalistas parece-nos existir enquanto uma alternativa produtiva e não totalizante frente à educação e à formação tradicional excludente. Assim, nos convida a agir e a imaginar o mundo de outra forma (KUMARAVADIVELU, 2016).

Em nossas aulas de língua estrangeira, ao lançarmos mão dos pressupostos que subjazem ao LC, também aprendemos que as "diferentes formas de interpretar a realidade são legitimadas e valorizadas conforme critérios construídos sócio-historicamente que podem ser coletivamente reproduzidos e aceitos ou questionados e modificados"10 (JORDÃO; FOGAÇA, 2012, p. 75, tradução nossa). As escolas e quaisquer espaços de formação, nesta perspectiva, tornam-se espaços de promoção de questionamentos, de

\footnotetext{
10 "different ways to interpret reality are legitimized and valued according to socially and historically constructed criteria that can be collectively reproduced and accepted or questioned and changed."
} 


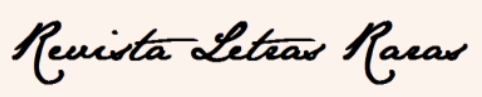

ISSN: $2317-2347$ - v. 8, n. 3 (2019)

rupturas e, principalmente, de negociação, seja de sentidos, seja de identidades, com vistas ao posicionamento crítico dos sujeitos ali presentes, alunos e/ou professores.

\section{A criticidade na formação de professores de inglês}

Antes de fazermos uma leitura dos dados gerados, explicamos que os participantes da pesquisa faziam parte do curso de Licenciatura em Letras: língua inglesa ${ }^{11}$ da Universidade Federal de Campina Grande (UFCG) e estavam, no momento da entrevista e da narrativa, matriculados na disciplina Estágio de Língua Inglesa: $3^{\circ}$ e $4^{\circ}$ ciclos do Ensino Fundamental, ofertada no sexto período do referido curso de graduação. Assim, utilizaremos as siglas AP1, AP2, AP3, AP4, AP5, AP6 para descrevermos a condição de alunos-professores dos participantes da pesquisa na IES investigada em um determinado momento histórico. Alunos enquanto licenciandos em processo de formação em nível superior e, professores por estarem na posição de estagiários (e mesmo de professores efetivos), vivenciando os desafios encontrados na profissão.

Justificamos a escolha das siglas por preservar de forma mais completa a identidade dos sujeitos, em atendimento e respeito à ética na pesquisa ${ }^{12}$. Outra ressalva que fazemos é que nossa adoção neste trabalho dos pressupostos do LC não implica que, em sala de aula de formação, os AP tenham estudado tal abordagem ou que seus professores formadores tenham explicitamente adotado tal perspectiva.

Evidenciamos, finalmente, que empreendemos uma investigação qualitativa, descritivo-analítica, de base etnográfica, dentro do paradigma interpretativista de pesquisa cujos instrumentos de geração de dados escolhidos para este recorte foram a entrevista semiaberta e a narrativa. A partir de tais dados, discutiremos a noção de criticidade eleita neste trabalho e como ela pode ser produtiva no processo de formação docente, de acordo com nosso entendimento. Isto é, observaremos como cada aluno-

\footnotetext{
${ }^{11} \mathrm{O}$ perfil deste curso consiste na indissociabilidade do tripé ensino-pesquisa-extensão, materializado em três eixos de formação. O eixo usuário objetiva capacitar o estudante a atribuir sentidos em LI, de forma adequada, em suas práticas sociais nos diversos contextos de comunicação. O eixo especialista objetiva fomentar uma "visão crítica e analítica das perspectivas teóricas e metodológicas adotadas nas investigações linguísticas e literárias" (UFCG, 2011, p. 14), ao passo que o eixo docente é voltado para a articulação entre teoria e prática "com vistas à análise crítico-reflexiva" do contexto em que está inserido. (UFCG, 2011, p. 14).

${ }_{12}$ A pesquisa em sua totalidade foi aprovada pelo Comitê de Ética em Pesquisa conforme Parecer $\mathrm{n}^{\circ}$ CAAE 37094614.0.0000.5182.
} 


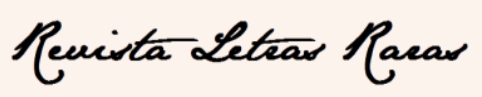

ISSN: $2317-2347$ - v. 8, n. 3 (2019)

professor em formação se engajou em atitudes críticas, apontando o que seria criticidade para eles.

Para responder ao objetivo posto neste artigo, decidimos observar as respostas dos AP em relação ao seu processo de formação inicial no curso de Letras, de modo que eles refletissem se sua visão quanto à língua inglesa e ao seu ensino havia mudado após o contato com a referida formação. Cientes estamos, porém, de que o desenvolvimento da criticidade 1) não se dá de forma linear ou completamente consciente, 2) não acontece somente no espaço educacional, 3) foge dos esforços e das capacidades dos professores formadores. Dito de outro modo, a criticidade é uma forma de agir no mundo que é aprendida cotidianamente e que dependerá do interesse, da constituição de cada um de nós enquanto sujeitos, do tempo de cada um, das comunidades interpretativas das quais fazemos parte, enfim, de todo um assemblage (DELEUZE, GUATTARI, 1995) que liga seres, emoções, racionalidades, vontades, histórias de vida, textos escutados e lidos durante nossa trajetória e que constitui a nossa formação.

Iniciando a exposição de nossos excertos, na fala de AP1 (Excerto 1), revelamos a problematização feita em torno da língua inglesa (doravante LI) e dos discursos que a ela são remetidos, ao mesmo tempo em que percebemos o processo de desconstrução dessa visão a partir de sua entrada na universidade, marcada pelo advérbio 'antigamente'. Como ele expõe:

\begin{abstract}
Excerto 1
AP1: Mudou, mudou bastante. Porque antes eu usava como uma ferramenta mesmo, e hoje em dia eu uso como uma ferramenta, mas é... refletindo, sempre refletindo. Por que é que a língua funciona assim? Por que é que nessa situação é que eu devo usar isso e não isso? Por que é que há estruturas que eu não aceito?... é... tem flexibilidade nessa estrutura ou não? dizem que não tem. Será mesmo que não tem? Você vai começando a a pensar nas verdades que vão lhe passando e duvidando delas, que é uma coisa que o curso também puxa muito. É a universidade lhe faz pensar demais assim... criticamente... Você começa a ser um sujeito mais crítico. Lógico que se você quiser [...] e o pa e o próprio papel da língua inglesa se torna muito mais crítico. Antigamente eu pensava: "Ah, é a língua inglesa que em qualquer lugar do mundo você chega e você pode usar". Não, nem sempre, mas mesmo quando é usada, que língua inglesa é essa? É aquela que você estudou da escola? Não é! O que é que tem de diferente nessa língua inglesa? [...] (Entrevista de AP1). ${ }^{13}$
\end{abstract}

\footnotetext{
${ }^{13}$ Esclarecemos que não fizemos quaisquer modificações nas falas aqui trazidas e que todos os destaques são nossos.
} 


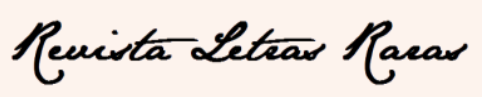

ISSN: $2317-2347$ - v. 8, n. 3 (2019)

Ao questionar a LI, AP1 demonstra sua compreensão de língua para além de um sistema fechado (por mais que fale em 'ferramenta'), não como uma entidade que tem vida independente de seus falantes. Demonstra sua noção de múltiplas línguas inglesas como modos de agir no mundo e aponta para como questões de poder e ideologias estão circundando esta língua. Observamos a partir desse excerto que ele não se contentou com as visões fixas e naturalizadas de língua, mas deu abertura ao dissenso e ao questionamento de verdades engessadas e que, como ele afirma, devem ser enfraquecidas ou ao menos localizadas.

AP1 indica no Excerto 1 que desenvolveu essa atitude questionadora frente aos fatos, linguísticos e não linguísticos, bem como ao entendimento da não garantia de uma formação crítica de seu alunado possibilitada pela universidade/programas de formação. Percebemos ainda o reconhecimento da mudança e a vivência da desconstrução das representações ideológicas na fala de AP1, confirmando sua postura de agente, segundo o LC. Quando assume o papel da LI sob um viés crítico, AP1 se questiona sobre a LI que é falada. Essa atitude de suspeita constante nos orienta a considerá-la enquanto manifestação de criticidade de acordo com LC de viés pós-estruturalista.

No Excerto 2, de maneira diversa a AP1, AP2 crê que a mudança vista na LI antes e depois de sua entrada na esfera universitária dá-se pela necessidade de maior "domínio" da língua por estar em posição de maior responsabilidade como professor de inglês. Em suas palavras:

\footnotetext{
Excerto 2

AP2: Mudou porque antes era antes eu gostava de inglês mas eu não tinha porquê e hoje não, eu consegui associar inglês a ensinar ao ensino e ... mudou no sentido que agora tem é como o inglês tem um objetivo pra mim, eu tenho necessidade de aprender mais inglês do que o que eu tinha que aprender no ensino fundamental, no ensino médio, então agora como eu vou ensinar eu tenho que tá ... tenho que aprender mais. (Entrevista de AP2).
}

Lemos no excerto que, para AP2, não é suficiente ser proficiente em LI para si, ora sim se torna fulcral um maior aprofundamento e maior confiança para ministrar aulas. Mesmo concordando com AP2 sobre a necessidade do docente se sentir bem no desconforto da sala de aula, ter conhecimentos também formais e ter responsabilidade e ética para lecionar (MENEZES DE SOUZA, 2011b), percebemos que o entendimento de criticidade para esses AP difere. Parece-nos que AP1 está mais centrada na 


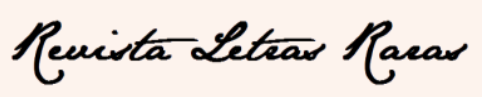

ISSN: $2317-2347$ - v. 8, n. 3 (2019)

problematização e no questionamento (PENNYCOOK, 2012), enquanto AP2 está mais posicionada em direção à docência como domínio da língua a ser ensinada (portanto parece ver língua como um sistema fechado), à aprendizagem e ao desenvolvimento de habilidades cognitivas mais profundas e individuais, como na leitura crítica.

AP3 parte para questões de língua e de contextos mais amplos que devem ser levados em consideração pelo professor em seu exercício profissional. Como relata:

\begin{abstract}
Excerto 3
AP3: Mudou... principalmente por conta do da questão do ensino... Eu diria se no começo... por exemplo... estaremos mais focado em ensinar a língua pela língua, agora a gente já tem uma perspectiva maior de se abarcar... Por exemplo... pode trazer músicas e inclusive inserir que a a a língua tá em qualquer lugar... inclusive até no próprio dia a dia de um estudante brasileiro na sua própria comunidade... Não tá totalmente além dele... tá tão perto da gente que a gente nem imagina... São aquelas questões até das próprias crenças que a gente vem construindo desde o ensino médio... desde que a gente começa a aprender e quando a gente chega aqui a gente começa a desconstruir. (Entrevista de AP3).
\end{abstract}

AP3 aponta uma mudança em direção ao alargamento de seus entendimentos sobre a língua, que antes estavam fechados na língua enquanto forma, estrutura. A mudança é ratificada no excerto elencado, dado que AP3 reconhece partir de um lugar e ir para outro no qual é necessária a ruptura com antigas visões fechadas (ensino da língua pela língua; pertença territorial de determinado idioma; supremacia de certos sotaques). AP3 confirma essa mudança de perspectiva como alguém que, antes de entrar na universidade, pensava que o curso preparava linguisticamente os graduandos, ao passo que atualmente vê outras questões, especialmente o ensino e tudo o que ele envolve eixos usuário, especialista e docente (ver nota de rodapé 11). Reconhece ainda a presença da LI fora de seus territórios legitimados, uma vez que ela está "em qualquer lugar... inclusive até no próprio dia a dia de um estudante brasileiro na sua própria comunidade" (Excerto 3). Isso, dentre outros aspectos, dá a possibilidade de trabalhar a língua de forma mais significativa e autêntica a partir das realidades locais dos alunos, elucidando também que o global é um local com poder e legitimidade.

Faz-se interessante e necessário ressaltar a desconstrução mostrada pelo próprio AP3 de suas crenças aprendidas, segundo ele, desde o Ensino Médio e que são questionadas e ressignificadas em seu processo de formação docente. $O$ termo 


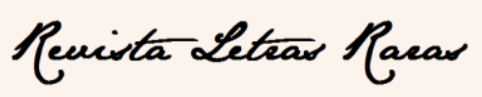

ISSN: $2317-2347$ - v. 8, n. 3 (2019)

desconstrução, advindo de Derrida (1991), vem, neste trabalho, baseado em Menezes de Souza (2011a), designar um exercício de desnaturalização do que é entendido como evidente e universal. Assim, vemos nesse exercício de desconstrução de saberes estanques, de crenças e de (pre)conceitos um exercício constante e mais do que necessário à prática docente, almejando à construção conjunta (a partir do outro) de conhecimento, práticas que corroboram os pressupostos do LC. Essa leitura não desconhece, contudo, outras interpretações e sentidos que o AP queira ter dado a sua fala. Apesar disso, não percebemos em suas falas um tom celebratório e acrítico do estatuto da LI no mundo. Nesse sentido, parece-nos que este AP está em crise, assumindo diversas posições identitárias e que lança luz a questões relevantes para ele e para sua formação por meio da reflexão. Em sua narrativa, ele reflete:

\begin{abstract}
Excerto 4
AP3: Com relação à minha atitude nos eixos usuário, especialista e docente, tenho tentado, respectivamente: i) observar e/ou modificar minha postura na participação das aulas; ii) analisar os aspectos positivos e negativos das metodologias adotadas pelos docentes; e, iii) aplicar os lados efetivos dos métodos de ensino dos professores durante minhas aulas de estágio, tentando refletir sobre os resultados obtidos para uma prática mais eficaz no contexto em foco. (Narrativa de AP3).
\end{abstract}

Com isso, queremos apontar para seu exercício de reflexão constante e a vivência que tende a perpassar todos os AP (e acrescentaria em todos nós) de não estar inteiramente na modernidade sólida nem na modernidade líquida, ou se estar em um ou em outro é produtivo, ou seja, de ver a crise (aplicação de métodos versus reflexão e questionamento) enquanto constitutiva do sujeito, como nos alertou Kumaravadivelu (2013).

AP5 rememora seus tempos de curso de idiomas para elaborar uma comparação com sua formação docente universitária. No Excerto 5, ele diz:

\title{
Excerto 5
}

AP5: Assim, antes quando eu fazia cursinho de idiomas, é como eu já havia falado, né? a gente só olha mais pra esse olhar gramatical, só de aprender as regras e conversar, a conversação. Quando a gente chega aqui na universidade, a gente tem outro olhar [...] nas escolas de idiomas não só aqui de Campina Grande mas como eu acho do Brasil eles sempre tem aquela perspectiva de você "ah, você quer aprender inglês, você quer aprender que inglês, o britânico ou o americano?" E quando chega aqui a gente vê que o brasileiro tem as suas particularidades de falar inglês, não é? O africano tem a sua particularidade de falar inglês. 


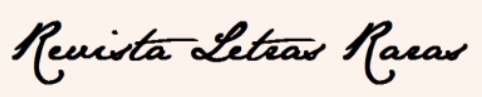

ISSN: $2317-2347$ - v. 8, n. 3 (2019)

Isso a gente vê assim de forma geral, que nã...é bom você ter assim aquele accent, o sotaque, mas mas é..cada indivíduo tem a sua identidade em termos de língua, então o brasileiro tem a sua particularidade de falar inglês também. (Entrevista de AP5).

AP5, no Excerto 5, relata sobre a questão que por muito tempo habitou o imaginário dos aprendizes de língua inglesa em relação aos cursos de idiomas e aos sotaques britânico e americano, rompendo com e descentralizando essa visão. Não podemos esquecer que ser capaz de falar uma língua significava saber imitar o falante nativo, devido à tradição audiolingualista, decorrendo disso a aceitação do modelo americano e/ou britânico como padrões a serem copiados (BARBOSA, 2007). Diferentemente, notamos aqui a tentativa de valorização da identidade cultural dos sujeitos, que não mais se submetem ao poderio dos países antes considerados detentores da língua, quais sejam Inglaterra e Estados Unidos.

Dito isso, AP5 demonstra compreender seu lugar, seu sotaque, as necessidades dos falantes brasileiros e o papel dessa língua para cada falante, apesar de essencializar as identidades e os sotaques dos falantes, quando não reflete sobre a diversidade que há dentro de um mesmo país, de um mesmo bairro, de um mesmo sujeito (Excerto 5).

Em suma, diante das falas de AP3 e AP5, destacamos o entendimento da aprendizagem situada e a relevância de uma formação universitária para redimensionar o ensino-aprendizagem da LI na Educação Básica, quando eles atentam para o brasileiro e suas necessidades individuais e coletivas para aprender inglês ou ainda quando percebem a LI como fazendo parte de um repertório maior presente no cotidiano dos alunos (JORDÃO, 2014, 2017). Assim, estes AP mostram-se capazes de atribuir sentido ao uso da língua, também como consequência de um ensino universitário que faz parte e utiliza elementos outros da cultura e da vivência dos alunos.

Como mostrado nos Excertos 3 e 4, AP3 reflete sobre suas crenças e a necessidade de desconstrução das mesmas, ampliando seu escopo de visão e inquietando-se quanto às representações de ordem absoluta que lhe foram repassadas e que devem ser contestadas (MENEZES DE SOUZA, 2011a), ao mesmo tempo em que AP5, no Excerto 5, também percebe o movimento em direção ao desenvolvimento de criticidade desse alunoprofessor e, em sua prática, tenta refletir sobre os fatos linguísticos a partir do conteúdo proposto. 


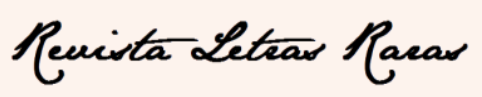

ISSN: $2317-2347$ - v. 8, n. 3 (2019)

Com relação às suas narrativas, chama a atenção como os AP decidiram destacar o relacionamento existente entre as disciplinas do curso de licenciatura, sobretudo para enfatizar que os conhecimentos estão interligados e devem se retroalimentar em todos os momentos em sua prática profissional. Para ilustrar, trazemos trechos de três AP.

AP1, por exemplo, ilustra que

\begin{abstract}
Excerto 6
Acredito que ao entrar no curso eu tinha uma visão deveras tradicionalista do ofício docente, a universidade me despertou para o fato de que ensinar é, na verdade, uma arte que envolve a mobilização de saberes que vai além do "domínio" da língua em si (se é que dominar uma língua é possível). O que se requer do estudante não é a mera capacidade de usar a língua, mas também entender seu funcionamento, sua história, a cultura que esta língua reflete e vários outros fatores que alicerçam o desenvolvimento e uso contínuo de uma língua que é viva e mutável. Além disso, subjacente a esta língua multifacetada notamse discursos e ideologias, isso tudo torna a tarefa de mediar o ensino de uma língua algo muito complexo. O curso nos desperta para esses fatores, que boa parte dos não especialistas em línguas podem ignorar, mas não deveriam. Afinal, mesmo o usuário precisa ter consciência do poder que a língua exerce em uma sociedade. (Narrativa de AP1).
\end{abstract}

Nessa fala, AP1 desconstrói sua visão de ser professor como sendo o domínio da língua o fator fundante e primordial da profissão, expandindo-a para uma que compreende a mobilização de saberes outros - linguísticos, culturais, pragmáticos -, configurando essa prática como complexa e desafiadora.

Dois ainda são os aspectos que sublinhamos nesse excerto: o primeiro é o questionamento 'se é que dominar uma língua é possível' e a visão de língua como algo 'vivo', 'mutável' e que tem 'poder' (Excerto 6). Essa problematização do termo 'dominar' pode ser caracterizada como uma manifestação de criticidade pelo fato de que perturba o lugar comum pregado pelos discursos hegemônicos de aprendizagem de língua estrangeira e de língua como produto, como sistema passível de ser estudado e dominado, por ser fechado. Essa asserção está imbrincada na segunda, na percepção da mudança e do poder da língua. Nessa concepção de língua, não é defendida a sua transparência/univocidade. Ao contrário, como é enfatizado, "subjacente a esta língua multifacetada notam-se discursos e ideologias" (Excerto 6).

Esses dois movimentos indicam uma formação voltada para o questionamento e não para a doutrinação e o treinamento (PENNYCOOK, 2012). Isto é, a partir desse relato, fazemos uma leitura de que o modo como os professores formadores conduzem 


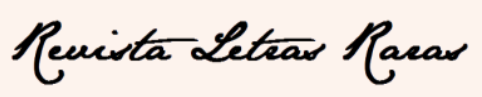

ISSN: $2317-2347$ - v. 8, n. 3 (2019)

suas aulas abarcando o contexto global e local e as identidades, dentre outros aspectos, favorece o desenvolvimento da criticidade desses AP, uma vez que aproveitam a existência de espaço em sala de aula para a promoção de discussões, planejamentos, avaliações entre pares, do professor e de si mesmo.

No Excerto 6, AP1 destaca dois dos três eixos que devem ser contemplados em sua formação, como indicado no Projeto Pedagógico do Curso, quais sejam: o usuário e o especialista. AP1, nesse ponto, expande a noção da competência do usuário para a do especialista, enfatizando a importância da formação de ambos com foco em sua criticidade e capacidade de análise e reflexão, quando afirma que o usuário da língua também deve "ter consciência do poder que a língua exerce em uma sociedade", e que seria este o papel da universidade para os especialistas, os que estão em formação. Como ressaltado por AP1, a compreensão da existência de uma gama de ideologias e de discursos que podem ser questionados, mudados ou mantidos na língua torna o papel do professor de LI muito mais complexo, percebendo que ele não é mais concebido como aquele que transmite seus conhecimentos, mas aquele que medeia relações de ensino e aprendizagem e tudo o que a língua envolve.

AP4 e AP6 por sua vez, corroboram a narrativa de AP1 quando escrevem:

\section{Excerto 7}

AP4: Dessa forma, acredito que uma disciplina está relacionada a outra, seja ela de preparação para a prática acadêmica ou direcionada para o aprendizado específico na LI, assim, uma contribuiu para a outra sendo os textos teóricos estudados muitas vezes reutilizados e aproveitados ao longo do curso. (Narrativa de AP4).

\section{Excerto 8}

AP6: Posso afirmar que as disciplinas que cursei até o presente momento se relacionam entre si especialmente no que diz respeito a formar professores que sabem trabalhar com a língua de forma crítica com o objetivo de contribuir para a formação de cidadãos, além de formar professores que refletem constantemente sobre a sua prática sempre a fim de aprimorá-la. (Narrativa de AP6).

Os Excertos 7 e 8 nos chamam a atenção para o caráter retroalimentativo e relacional das disciplinas cursadas pelos AP e a sua percepção, nem sempre tão evidente, do diálogo existente entre as mesmas em prol da formação do professor. Além disso, notamos que os AP situam a conexão teoria e prática como central e de importância primeira no curso, haja vista as disciplinas estarem conectadas com o componente 


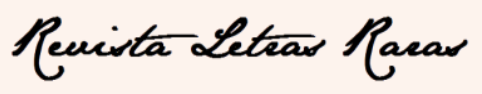

ISSN: $2317-2347$ - v. 8, n. 3 (2019)

prático ${ }^{14}$ desde o início do curso até o último período $\left(9^{\circ}\right)$, e com o Estágio desde o $5^{\circ}$ período, totalizando 420 horas de prática, o que os auxilia em sua prática atual e futura, uma vez que esta não pode ser vazia, mas sim informada teórica e criticamente.

Para além de professores, conforme AP6 destaca, os que ali estão sendo formados têm seus estudos voltados à formação crítica e reflexiva, que tenciona a construção, e não a transmissão, do conhecimento com o aluno (JORDÃO, 2010). Essa perspectiva é proposta pelo LC e, desse modo, também é vista na pós-modernidade como responsiva à crise educacional por permitir o movimento e reconhecer a fluidez e a instabilidade do conhecimento (Excerto 8). Outro ponto de grande importância citado foi a necessidade da formação de alunos cidadãos e professores reflexivos e atuantes, isto é, que questionam, pensam e agem sobre o contexto do qual fazem parte, dentro e fora da escola, como apontam Jordão (2010), Menezes de Souza (2011a, 2011b) e Freitas (2004). Pelos pontos destacados, pensamos que as reflexões postas pelos AP são representativas de criticidade em suas diferentes formas. Entretanto, pelo fato de os AP entenderem os saberes como interdependentes e destacarem a formação enquanto um espaço para reflexão e para práticas mais localizadas (MENEZES DE SOUZA, 2011a, JORDÃO, 2013, 2014, 2017), consideramos que tais reflexões estão alinhadas com o LC.

\section{Conclusões}

Neste artigo, propusemos ler as respostas a uma entrevista semiaberta e a narrativas escritas por alunos em seu curso de formação a partir das lentes do LC, por entendermos tal abordagem enquanto problematizadora e responsiva às ressignificações impostas pelos tempos líquido-modernos.

No ambiente pesquisado, ressaltamos, não há indícios documentais sobre a adoção de algum método específico, tendo em vista que o currículo compreende a impossibilidade dos métodos de abarcarem todos os contextos, responsabilizando o professor de fazer uso de instrumentos que lhe forem mais adequados a seu contexto específico de sala de aula. Dadas às discussões fomentadas no seio da universidade sobre

\footnotetext{
14 Estas informações fazem referência à carga horária e à configuração do currículo no momento de realização da pesquisa.
} 


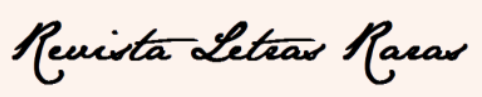

ISSN: 2317-2347 - v. 8, n. 3 (2019)

essas mudanças prementes, vemos nas atitudes dos participantes uma prática por vezes heterogênea, ancorada em perspectivas ora mais sólidas, ora mais fluidas.

Diante dos dados gerados, entendemos que as falas dos AP em geral parecem revelar movimentos críticos que se alinham às perspectivas do LC de viés pósestruturalista. Neste sentido, fazemos uma leitura conscientemente contingente que, em situação de estudo, os AP manifestam criticidade principalmente a partir de falas que revelam questionamentos, desnaturalização e construção de entendimentos outros em um movimento formativo processual e não linear.

Os AP percebem a relevância da conexão que deve ser estabelecida entre a teoria e a prática, destacando o papel do seu espaço de formação como um local privilegiado para tal. Uma sala de aula cujo ensino ultrapassa e supera o lugar comum das regras gramaticais e que concebe a língua como uma prática social e não como um sistema de regras descontextualizadas e com fim em si mesmo. Essa visão se faz presente e é um dos objetivos do currículo em vigência: a integração e retroalimentação das disciplinas, de modo a relacionar teoria e prática durante todo o curso (cf. UFCG, 2011).

No lócus de estudo dos AP, a língua inglesa, seu ensino, sua literatura ou demais aspectos e fenômenos linguísticos que o curso de Letras - Língua Inglesa abarca são ministrados dentro de uma perspectiva que contempla e privilegia a reflexão e a problematização para a transformação dos sujeitos aprendentes. Destarte, desde os instrumentos utilizados em sala de aula, ao modo como se ensina e às escolhas teóricas assumidas pelos professores formadores, a criticidade pode ser revelada. É fato que esta se apresenta de maneira distinta em cada AP, pois o que se estuda em sala de aula atinge as pessoas de diversos modos e estas, por possuírem experiências e entendimentos diferentes, constroem sentidos de forma local, mais ou menos validados. Contudo, ao sentirem-se implicados no ensino, os AP podem vir a agir criticamente a partir de espaços de discussão e crescimento, seja como cidadãos, seja como profissionais.

Não é nosso desejo classificar a "validade" dos tipos de criticidade descritos na primeira parte deste artigo, menos ainda implicar que há um modelo de criticidade a priori que deve ser alcançado. Se assim o fizéssemos, estaríamos contradizendo a perspectiva pós-estruturalista sobre a qual nos apoiamos. Intentamos sobremaneira lutar contra as consequências da modernidade sólida com vistas a desenvolver modos alternativos de conhecer e agir no mundo, por isso a adoção, não sem reflexão e reflexividade, do LC. 


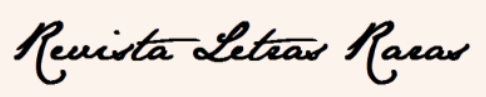

ISSN: $2317-2347$ - v. 8, n. 3 (2019)

Diante desses resultados, ressaltamos que os espaços de formação confirmam-se como propícios ao desenvolvimento crítico do formando para a ruptura, a contestação, a afirmação e a agência sobre a realidade da qual faz parte, uma vez que favorecem o debate e a discussão com o objetivo de que esse professor em formação desenvolva a percepção de múltiplas verdades, de diversificadas representações e discursos que concorrem para a hegemonia de algum discurso privilegiado, sendo seu (potencial) dever a agência - o agir informado pela criticidade (JORDÃO, 2010).

\section{REFERÊNCIAS}

ANDREOTTI, V.; MENEZES DE SOUZA, L. M. T. Critical education and postcolonialism. In: PETERS, M. (Ed). Encyclopedia of educational philosophy and theory. Singapore: Springer, 2016, p. 1-6.

BARBOSA, J. R. A. Abordagem do professor de inglês em relação aos "erros" de pronúncia dos aprendizes. 2007. 213f. Tese (Doutorado em Linguística). Universidade Federal do Ceará, Fortaleza.

BAUMAN, Z. Modernidade líquida. (Tradução de Plínio Dentzien) Rio de Janeiro: Jorge Zahar Ed., 2001.

Tempos líquidos. (Tradução de Carlos Alberto Medeiros) Rio de Janeiro: Jorge Zahar Ed., 2007.

BHABHA, H. K. O local da cultura. (Tradução de Myriam Ávila, Eliana Lourenço de Lima Reis, Gláucia Renate Gonçalves). Belo Horizonte: Editora UFMG, 1998.

CERVETTI, G.; PARDALES, M. J.; DAMICO, J. S. A tale of differences: comparing the traditions, perspectives and educational goals of critical reading and critical literacy. Reading Online, v. 4, n. 9, 2001. Disponível em <http://www.readingonline.org/articles/art_index.asp?HREF=cervetti/index.html> Acesso em 22 set. 2018.

COSTA, E. G. de M. Práticas de letramento crítico na formação de professores de línguas estrangeiras. Revista Brasileira de Linguística Aplicada, Belo Horizonte, v. 12, n. 4, p. 911- 932, 2012.

COSTA, M. A. M. Do sentido da contingência à contingência da formação: um estudo discursivo sobre a formação de professores de inglês. 2008. 231f. Tese (Doutorado em Letras) Faculdade de Filosofia Letras e Ciências Humanas, Universidade de São Paulo, São Paulo.

DELEUZE, G.; GUATTARI, F. Mil platôs: capitalismo e esquizofrenia. (Tradução de Aurélio Guerra Neto e Célia Pinto Costa). Rio de Janeiro: Ed. 34, 1995.

DERRIDA, J. Margens da filosofia. (Tradução de Joaquim Torres Costa e Antônio M. Magalhães). Campinas: Papirus, 1991. 


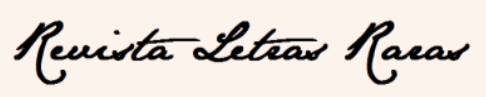

ISSN: $2317-2347$ - v. 8, n. 3 (2019)

DUBOC; A. P. M.; FERRAZ, D. M. Letramentos críticos e formação de professores de inglês: currículos e perspectivas em expansão. Revista X, Curitiba, vol. 2, p. 19 - 32, 2011.

DUBOC, A. P. M. Atitude curricular: letramento crítico nas brechas da formação do professor de inglês. 2012. 258f. Tese (Doutorado em Letras). Universidade de São Paulo, São Paulo.

; FERRAZ, D. M. Reading ourselves: placing critical literacies in contemporary language education. Revista Brasileira de Linguística Aplicada, Belo Horizonte, v. 18, n. 2, p. 227-254, 2018.

FABRÍCIO, B. F. Linguística aplicada e visão de linguagem: por uma INdisciplinaridade radical. Revista Brasileira de Linguística Aplicada, Belo Horizonte, v. 17, n. 4, p. 599617,2017

FREIRE, P. Pedagogia do oprimido. São Paulo: Paz e Terra, 1974.

Pedagogia da tolerância. São Paulo: Editora Unesp, 2005.

FREITAS, M. A. Educação e ensino de língua estrangeira hoje: implicações para a formação de seus respectivos profissionais e aprendizes. In: ABRAHÃO, M. H. V. (Org.). Prática de ensino de língua estrangeira: experiências e reflexões. Campinas, SP: Pontes; ArteLíngua, 2004, p. 117-130.

JORDÃO, C. M. A posição do professor de inglês no Brasil: hibridismo, identidade e agência. Revista Letras \& Letras, v. 26, n. 2, p. 427 - 442, 2010.

; FOGAÇA, F. C. Critical literacy in the English language classroom. D.E.L.T.A., v. 28, n. 1, p. 69-84, 2012.

Abordagem comunicativa, pedagogia crítica e letramento crítico - farinhas do mesmo saco? In: ROCHA, C. H.; MACIEL, R. F. Língua estrangeira e formação cidadã: por entre discursos e práticas. Campinas: Pontes, 2013, p. 69-90.

Aprendendo língua estrangeira com o professor Jacotot: criticidade na pedagogia crítica e no letramento crítico. In: MATEUS, E.; BUENO, N. (Org.) Estudos críticos da linguagem e formação de professores/as e línguas: contribuições teórico-metodológicas. São Paulo: Pontes, 2014, p. 1-13.

Entrevista com Clarissa Jordão. Entrevista concedida a Francisco Fogaça, Denise Hibarino, Denise Kluge. Revista X, Curitiba, v. 12, n. 1, p. 187-194, 2017.

KUMARAVADIVELU, B. Individual identity, cultural globalization, and teaching English as an international language: the case for an epistemic break. In: ALSAGOFF, L. et al. (Editors) Principles and practices for teaching English as an international language. New York: Routledge, 2012, p. 9-27.

(Re)visioning language teacher education. In:

. Language teacher education

for a global society: a modular model for knowing, analyzing, recognizing, doing and seeing. New York and London: Routledge, 2013.

. The decolonial option in English teaching: can the subaltern act? TESOL Quarterly, v. 50, n. 1, p. 66-85, 2016.

LANKSHEAR, C.; KNOBEL, M. New literacies: changing knowledge and classroom research. Buckingham: Open University Press, 2003. 


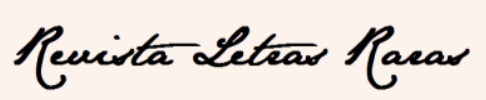

ISSN: $2317-2347$ - v. 8, n. 3 (2019)

LOPES, C. R. Repensando os saberes: mudanças nos paradigmas epistemológicos e a formação de professores de língua estrangeira. RBLA, Belo Horizonte, v. 13, p. 941-962, 2013.

LUKE, A.; FREEBODY, P. Critical literacy and the question of normativity. In: MUSPRATT, S.; LUKE, A.; FREEBODY, P. (Eds.) Constructing critical literacies. St. Leonards: Hampton, Press, 1997.

MATTOS, A. M. de A. O ensino de inglês como língua estrangeira na escola pública: novos letramentos, globalização e cidadania. 2011. 262 f. Tese (Doutorado em Estudos Linguísticos e Literários em Inglês). Departamento de Línguas Modernas, Universidade de São Paulo, São Paulo.

MENEZES DE SOUZA, L. M. T. Para uma redefinição de letramento crítico: conflito e produção de significação. In: MACIEL, R. F.; ARAUJO, V. A. (Orgs.) Formação de professores de línguas: ampliando perspectivas. Jundiaí: Paco Editorial, 2011a.

O professor de inglês e os letramentos no século XXI: métodos ou ética? In: JORDÃO, C. M.; MARTINEZ, J. Z.; HALU, R. C. (Orgs.) Formação "desformatada": práticas com professores de língua inglesa. Campinas: Pontes, 2011b.

MONTE MÓR, W. Crítica e letramentos críticos: reflexões preliminares. In: ROCHA, C. H.; MACIEL, R. F. Língua estrangeira e formação cidadã: por entre discursos e práticas. Campinas: Pontes, 2013, p. 31- 50.

Learning by design: reconstructing knowledge processes in teaching and learning practices. In: COPE, B.; KALANTZIS, M. (Eds.). A pedagogy of multiliteracies. London: Palgrave Macmillan, 2015, p. 186-209.

PENNYCOOK, A. Language and mobility: unexpected places. Bristol/Buffalo/Toronto: Multilingual Matters, 2012.

ROJO, R. H. R. Letramentos múltiplos, escolar e inclusão social. São Paulo: Parábola, 2009.

SILVA, J. E. Formação de professores em tempos (pós)modernos: a criticidade em foco. 2015. 180 f. Dissertação (Mestrado em Linguagem e Ensino), Unidade Acadêmica de Letras, Universidade Federal de Campina Grande, Campina Grande.

; COSTA, M. A. M. Entre a teoria e a prática: a formação docente na pósmodernidade. In: ARAÚJO, N. S.; PINHEIRO-MARIZ, J. (Org.) Línguas, literatura e ensino: reflexões da contemporaneidade. São Luís: EDUFMA, 2017, p. 101-125.

SOUSA SANTOS, B. Para além do pensamento abissal: das linhas globais a uma ecologia de saberes. Novos estudos, v. 79, novembro, 2007.

SOUSA SANTOS, B. The end of the cognitive empire: the coming of age of epistemologies of the South. Durham: Duke University Press, 2018.

SPIVAK, G. C. Righting Wrongs. The South Atlantic Quarterly, New York, v. 103, n. 2, p. 523-581, 2004.

STREET, B. Literacy in theory and practice. Cambridge: Cambridge University Press, 1984. 


\section{Revista Letear Racar}

ISSN: $2317-2347$ - v. 8, n. 3 (2019)

. What's "new" in New Literacy Studies? Critical approaches to literacy in theory and practice. Current Issues in Comparative Education, Columbia University, v. 5, n. 2, 2003.

Letramentos sociais: Abordagens críticas do letramento no desenvolvimento, na etnografia e na educação. (Trad. de Marcos Bagno). São Paulo: Parábola, 2014.

UNIVERSIDADE FEDERAL DE CAMPINA GRANDE. (2011). Projeto pedagógico curricular do curso de Letras língua inglesa. Campina Grande: Unidade Acadêmica de Letras/UAL/UFCG. 


\section{Reuista Leteas Pacas}

ISSN: $2317-2347$ - v. 8, n. 3 (2019)

ANEXOS

\section{A. Parecer do comitê de ética}

\section{HOSPITAL UNIVERSITÁRIO ALCIDES CARNEIRO / UNIVERSIDADE FEDERAL DE}

\section{PARECER CONSUBSTANCIADO DO CEP}

\section{DADOS DO PROJETO DE PESQUISA}

Titulo da Pøsquisa: UM OLHAR SOBRE A FORMAÇÅO CRITICA DO PROFESSOR DE LINGUA INGLESA NA POS-MODERNIDADE

Pesqulsador: Jhullane Evelyn da Silva

Área Tematica:

Versa:

CAAE: 37094514.0 .0000 .5182

Institulçaso Proponente:UNIVERSIDADE FEDERAL DE CAMPINA GRANDE

Patrocinador Principal: Financlamento Proprio

\section{DADOS DO PARECER}

Número do Parecer: 831.405

Data da Relatorla: 28/10/2014

Apresentaçaso do Projeto:

A proposta do trabaino emerge de indagaçăo presente no cotidlano de formaçăo de professores e ressurge em melo ao contexto da pos-modernidade e da ascensăo da lingua inglesa como lingua Intemacional (PENNYCOOK, 1994), que e a formaçăo critica do professor de ingles trente a todas as mudanças que vem ocorrendo na socledade e da necessidade desta lingua para a participaçăo na vida soclal globallzada. Entendendo que a formaç5̆o iniclal deve fornecer instrumentos outros que preparem o profissional para agir de acordo com a demanda da socledade em consonancla com o contexto em que vivemos, buscamos verificar em que medida os alunos em formaçăo Inıclal de uma unlversidade publica no Estado da Paraba apresentam marcas de criticidade em sua pratica pedagogica. Para tanto, almejamos tambem investigar como esses alunos planejam suas aulas levando em consideraçăo suas refexbes tecricas desenvolvidas ao iongo do curso, identincar as diferentes perspectivas dos alunos no que se refere ao ensino critico de Lingua Inglesa e ampllar a discussáo da area de formaçăo critica de professores de Lingua Inglesa. Com este Intento, nos apolamos em autores como Bauman $(2001,2005)$ para tratar da pos-modemidade e KIncheloe (1997) que une a pos-modernidade com o ensino de Ingles; Molta Lopes (1996, 2010, 2005), Pennycook (1994), Graddol (2006), Rajagopalan (2003, 2005) e Lacoste (2005) para discutir o ingles atualmente; New Londion group (2000), Luke e Freebody (1997), Gee (1991, 2000), Cope e

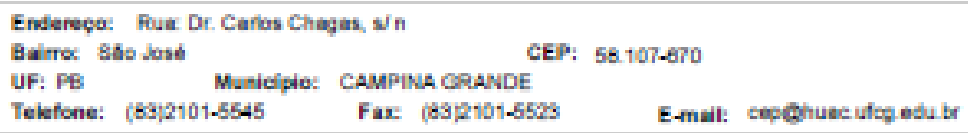


ISSN: $2317-2347$ - v. 8, n. 3 (2019)

\section{HOSPITAL UNIVERSITÁRIO \\ ALCIDES CARNEIRO / UNIVERSIDADE FEDERAL DE}

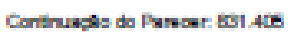

Kalantzis (2000), Monte Mor (2013), Menezes de Souza (2011) e Jordalo (2010) para tratar de criticldade e letramentos. Nessa perspectiva, considera-se a attude de questionamento, de crlaçăo de conhecimento, de negaçăo de verdades absolutas, dentre outras como de suma importancla no processo de formaçăo de professores de ingles, que exercem papel fundamental na formaçăo da socledade em geral.

\section{Objettvo da Pesqulsa:}

Oojetivo Primario:

Verificar em que medida os alunos em formaçăo iniclal de uma universidade pablica no Estado da Paraba manlfestam criticidade em sua pratica

pedagogica.

Cojetivo Secundarlo:

Investigar as marcas de criticidade na pratica pedagogica de alunos professores, tendo por base as perspectivas do letramento critico; Identificar as

diferentes perspectivas dos alunos professores no que se refere ao ensino critico de Lingua Inglesa Amplar a discusstó da area de formaçăa critica

de protessores de Lingua Inglesa.

Avallaçăo dos Rlscose Beneficlos:

A proponente demonstra conhecer os riscos envolvidos na pesqu'sa no que conceme ao desconforto gerado pela presença da pesqulsadora no amblente pesqulsado, porem no documento "Informaçøes Basicas" nota-se a ausencla de referencla as consequenclas que porventura adviriam da quebra de sigllo das Identidades dos sujeltos participantes. Afirmaçăo esta presente, contudo, na follha de rosto do processo. Os beneficios săo Indlcados de forma clara, evidenclando o ganho pedagoglco no processo ensinoaprendizagem dos professores de L.I. em formaçăo.

Comentarios $\theta$ Consideraç0 $\theta$ sobre a Pesqulsa:

A pesquisa esta bem estruturada em seus aspectos eticos, metodologicos e formals, com beneficlos claramente dellmitados para o campo de conhecimento abordado, bem como o controle de riscos.

Consideraçסөs sobre 08 Termos de apresentaçà obrigatorla:

Todos os termos estäo presentes e devidamente preenchidos.

Recomendaçoes:

Recomenda-se: a inserçăo de um resumo no projeto detalhado; o esclarecimento soore a forma de seleçăo dos sujeltos participantes dentre a turma de estudantes selecionada; determinar se a

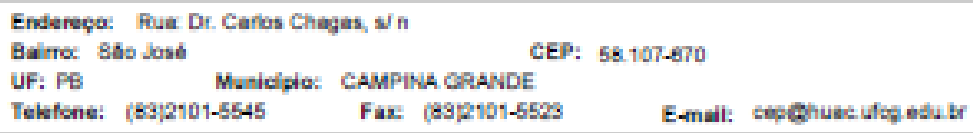




\section{HOSPITAL UNIVERSITÁRIO \\ ALCIDES CARNEIRO / \\ UNIVERSIDADE FEDERAL DE}

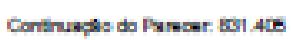

turma sera do sexto ou setimo periodo do curso, Informaç̧5̆o que ora figura de uma maneira ora de outra; delxar mals claro qual instrumento de analse sera usado para coleta de informaçbes no relatorio de estaglo (analse de conteúdo?).

Conclusరes ou Pendânclas $\theta$ Llsta de Inadequaç0es:

O projeto segue os parametros sollcltados por este CEP. As recomendaçbes visam apenas o complemento de informaçbles.

situaçăa do Parecer:

Aprovado

Necesalta Apreclaçåo da CONEP:

Nấ

Consideraçסes Finals a criterio do CEP:

Considerando o parecer da relatoria o protocolo fol considerado APROVADO ad referendum.

CAMPINA GRANDE, 14 de Outubro de 2014

Assinado por:

Marla Teresa Nascimento Sllva

(Coordenador)

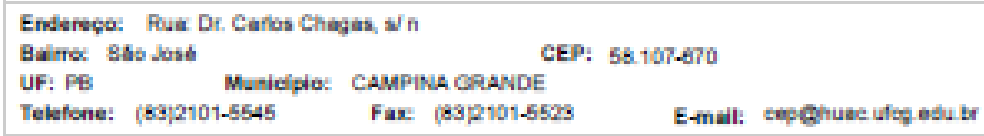

Paghe $\cos$ de 